Katarzyna Budzynska et al.*

Polish Academy of Sciences

\& University of Dundee

ORCID 0000-0001-6640-7207

\title{
WARSAW ARGUMENTATION WEEK (WAW 2018) ORGANISED BY THE POLISH SCHOOL OF ARGUMENTATION AND OUR COLLEAGUES FROM GERMANY AND THE UK, 6TH-16TH SEPTEMBER 2018
}

\begin{abstract}
In September 2018, the ArgDiaP association, along with colleagues from Germany and the UK, organised one of the longest and most interdisciplinary series of events ever dedicated to argumentation - Warsaw Argumentation Week, WAW 2018. The eleven-day 'week' featured a five day graduate school on computational and linguistic perspectives on argumentation (3rd SSA school); five workshops: on systems and algorithms for formal argumentation (2nd SAFA), argumentation in relation to society (1st ArgSoc), philosophical approaches to argumentation (1st ArgPhil), legal argumentation (2nd MET-ARG) and argumentation in rhetoric (1st MET-RhET); and two conferences: on computational models of argumentation (7th COMMA conference) and on argumentation and corpus linguistics (16th ArgDiaP conference). WAW hosted twelve tutorials and eight invited talks as well as welcoming over 130 participants. All the conferences and workshops publish pre- or post-proceedings in the top journals and book series in the field.
\end{abstract}

\section{Introduction}

The Warsaw Argumentation Week, WAW2018 (6-16 September, 2018), was a series of events dedicated to a variety of aspects, dimensions and approaches to argumentation (http://waw2018.argdiap.pl/). Its aim was to provide a platform for discussion between researchers representing a wide range of disciplines, who try to understand this crucial, fascinating, yet extremely difficult, communication phenomenon. The WAW series combined events associated with two communities - COMMA (Computational Models

\footnotetext{
* See last page for full list of authors.
} 
of Argument) and ArgDiaP (Argumentation, Dialogue, Persuasion). Among the WAW participants there were over a hundred researchers representing leading institutions from 20 countries in Europe, Asia, Africa and both Americas, amongst whom $30 \%$ of participants were talented PhD students whose research is focused on Natural Language Processing, Artificial Intelligence and deep learning techniques.

WAW 2018 comprised eight events: the interdisciplinary 3rd SSA graduate school (6-10 Sept); three COMMA workshops (11 Sept): on formal argumentation, argumentation \& society, and argumentation \& philosophy; the 7th COMMA conference (12-14 Sept); two workshops co-organised by ArgDiaP and the Polish Rhetorical Society (15 Sept) on legal argumentation, and on rhetoric; and the 16th ArgDiaP conference (16 Sept) on "Argumentation and Corpus Linguistics". The events included invited talks by prominent experts in the area and provided the opportunity to submit papers to a variety of pre- or post-proceedings in journals such as Argumentation (Springer), Argument \& Computation (IOS Press) and the Journal of Applied Logics - IfCoLoG Journal of Logics and their Applications (College Publications). Warsaw Argumentation Week was hosted by a number of academic institutions and departments in Warsaw and was coordinated by several researchers from the Polish School of Argumentation in cooperation with colleagues from Germany and the UK.

\section{Computational Models of Argument, COMMA}

\subsection{COMMA Community}

The COMMA community gathers a large international academic community interested in computational aspects of argumentation (http://com ma.csc.liv.ac.uk/). Originating from the EU ASPIC project that sought to further the state of the art in computational models of argumentation inference, decision making and dialogue, the inaugural conference took place in 2006 in Liverpool. Subsequently, COMMA conferences have been organised successfully every two years. Since 2014, COMMA has been collocated with the Summer School on Argumentation (SSA) and since 2016, with themed COMMA workshops. A distinguishing feature of the community is the extent to which its researchers interface formal logic and computational models with more human orientated uses of argument, both in the context of individual agent reasoning and decision making, and in dialogue. This is reflected in the series of events organised as part of the COMMA conference. 


\subsection{COMMA Summer School}

The Third Summer School on Argumentation: Computational and Linguistic Perspectives (SSA 2018) was held from 6th to 16th September 2018 at the Warsaw University of Technology (http://ssa2018.argdiap.pl/). The main aim of SSA 2018 was to provide attendees with a solid foundation in computational and linguistic aspects of argumentation and the emerging connections between the two. Furthermore, attendees had a chance to gain experience in using various tools for argument analysis and processing, including hands-on experience and practical tasks for students.

The school included tutorials, the Student Session and various social events for networking opportunities. The programme consisted of four types of tutorials: (1) introduction to argumentation theory; (2) presentation of COMMA leading themes (COMMA tutors); (3) presentation of links between argumentation studies and research in Poland (Warsaw tutors); and (4) presentation of contemporary advances in argumentation theory (SSA tutors). As well as COMMA invited speakers, Francesca Toni and Marcello D'Agostino (see Section 2.3), the tutorials were given by leading experts in different approaches to argumentation: Michał Araszkiewicz (Faculty of Law and Administration, Jagiellonian University, Poland), Floris Bex (Department of Information and Computing Sciences, Utrecht University \& Tilburg Institute for Law and Society, Tilburg University, Netherlands), Katarzyna Budzyńska (Centre for Argument Technology, Polish Academy of Sciences \& University of Dundee, Poland \& UK), Kamila DębowskaKozłowska (Department of Pragmatics of English, Adam Mickiewicz University in Poznań, Poland), Barbara Dunin-Kęplicz (Institute of Informatics, University of Warsaw, Poland), Jean Goodwin (Department of Communication, North Carolina State University, US), Dariusz Kalociński (Institute of Philosophy, University of Warsaw, Poland), Marcin Koszowy (Faculty of Law, University of Białystok \& Polish Academy of Sciences, Poland), Tim Norman (Electronics and Computer Science, University of Southampton, UK), Martín Pereira-Fariña (Department of Philosophy and Anthropology, University of Santiago de Compostela, Spain), Manfred Stede (Discourse Research Lab, University of Potsdam, Germany), Dominik Sypniewski (Faculty of Administration and Social Sciences, Warsaw University of Technology, Poland), Andrzej Szalas (Institute of Informatics, University of Warsaw, Poland and Department of Computer and Information Science, University of Linköping, Sweden).

The SSA's Student Session was organised in order to provide a unique opportunity for students taking part in SSA to gain experience in presenting their work and to gather feedback concerning their ongoing scientific 
projects. It consisted of the contributed talks session and the mentoring session. On the basis of long abstracts, 8 talks were accepted for the contributed talks session. Talks addressed the $\mathrm{PhD}$ projects of participants including the objective, motivation and significance of their work. Each author had 20 minutes for the presentation (including discussion). The variety of topics covered argumentation, dialogue and persuasion. The most outstanding talk (B. Yun's "How Can You Mend a Broken Inconsistent KBs in Existential Rules Using Argumentation") was awarded the Best SSA2018 Paper Award. The mentoring session provided the opportunity to discuss submissions in further detail and to receive more feedback from SSA tutors. Six tutors took part in the mentoring session (Floris Bex, Katarzyna Budzyńska, Tim Norman, Martín Pereira-Fariña, Marcin Koszowy and Jean Goodwin). Each student had the opportunity to consult two of them.

\subsection{COMMA Workshops}

This year there were three workshops collocated with the COMMA conference: 2nd SAFA (International Workshop on Systems and Algorithms for Formal Argumentation), 1st ArgSoc (Argumentation and Society) and 1st ArgPhil (Argumentation and Philosophy).

Algorithmic aspects of computational models of argumentation are an important area within the field of formal argumentation, as witnessed by the popularity of the International Competition on Computational Models of Argumentation (ICCMA). The Second International Workshop on Systems and Algorithms for Formal Argumentation (SAFA 2018, http://safa2018.argumentationcompetition.org) is the second instance of a workshop series aiming at complementing the competition by providing a forum to present and discuss both systems and algorithms dealing with all aspects of computational argumentation, in particular those approaches addressing the tracks of the competition. A first workshop had been organised in 2016. SAFA 2018 received seven submissions and six of them were accepted as regular papers for the workshop proceedings (see http://ceur-ws.org/Vol-2171). The topics of the accepted papers included algorithmic approaches for bipolar, set-based, and value-based argumentation frameworks, as well as analytical investigations on ICCMA benchmarks and general argumentation frameworks. The workshop also featured an invited keynote speech by Matti Järvisalo entitled "SAT for Argumentation" and a special presentation on the upcoming competition ICCMA2019 (http://www.iccma2019.dmi.unipg.it).

The first Argumentation and Society (ArgSoc) workshop provided a platform for the presentation and discussion of ongoing research in- 
vestigating the impact of argumentation research on society at large (http://comma2018.argdiap.pl/workshops/workshop-2/). In particular, the workshop encouraged research linking computational and informal approaches to argumentation with the social sciences such as theoretical and experimental psychology, sociology, media and communication studies, law, medicine, politics and education. The workshop took place on the morning of Tuesday, 11th Sept and attracted over 40 participants. There were nine interdisciplinary talks delivered, followed by a panel discussion on the opportunities and challenges for exploiting argumentation research in applications for society. Initial two-page abstract submissions are being extended for a 2019 special issue of the Argument $\&$ Computation journal (jointly with accepted publications from ArgPhil).

The first Argumentation and Philosophy (ArgPhil) workshop was dedicated to the discussion of work-in-progress, bringing together the traditional subfields of philosophy (ethics, epistemology, logic, etc.) and the COMMA community (http://comma2018.argdiap.pl/workshops/workshop$3 /$ ). A visit to the statues of four famous Polish logicians in the library of the University of Warsaw set the stage for the opening keynote by Michal Araszkiewicz and Marcin Koszowy. The well-attended (around 30-40 participants at all times) afternoon of 11th Sept comprised seven more talks, addressing a variety of topics, with some of the presentations leading to particularly engaged debate - as it turns out, the prospect of impending doom brought on by out-of-control AI is a guarantee for a lively discussion.

\subsection{COMMA Conference}

The COMMA conferences are a regular forum for presentation and exchange of the latest research results related to computational aspects of argumentation (http://comma2018.argdiap.pl/). Initiated in 2006, the first conference was organised in Liverpool and the success of the event led to the establishment of biennial COMMA conferences hosted in: Toulouse, France (COMMA 2008), Desenzano del Garda, Italy (COMMA 2010), Vienna, Austria (COMMA 2012), Pitlochry, Scotland (COMMA 2014) and Potsdam, Germany (COMMA 2016). COMMA 2018 was hosted by the Polish Academy of Sciences in Warsaw and chaired by Sanjay Modgil, King's College London, UK, and Katarzyna Budzyńska, Centre for Argument Technology, Polish Academy of Sciences \& University of Dundee, UK.

This year's edition of the COMMA conference welcomed outstanding experts whose research perfectly concurred with the aims and scope of the meeting: Marcello D'Agostino (Department of Philosophy, University of Milan, Italy), Noam Slonim (IBM Haifa Research Lab, Israel) and Francesca 
Toni (Department of Computing, Imperial College London, UK). These speakers represented a variety of concerns relevant to computational models of argument; notably, revision of scientific theories, and AI technologies (such as the IBM Project Debater) that utilise arguments extracted from data.

Since the introduction of the first software demonstration session to the COMMA programme in 2008, the popularity of this event has continued to grow, with COMMA 2018 very much carrying on this trend. A total of eighteen demonstrations (three connected to papers in the main conference, and fifteen submitted as stand-alone demonstration abstracts) were showcased, increasing from fourteen in 2016. The demonstrations given spanned areas including: collaborative and social systems based on argumentation; simulations of dialogue-based argumentation; argumentation-based agents and multi-agent systems; and argument mining systems. For the first time ever, those demonstrating were also joined by a range of carefully selected industry attendees demonstrating how argumentation is used within their software, and fostering future partnerships between industry and academia.

The conference's main programme also covered a wide area of key topics in computational argumentation, including work on algorithm development, innovative applications, argumentation-based models of dialogue, and abstract argument frameworks, whose various types of argument relations reflect the diversity of human uses of argument. Amongst submissions accepted for COMMA there were 25 long papers and 17 short papers (out of a total of 70 submissions) published in the volume Frontiers in Artificial Intelligence and Applications, IOS Press (Modgil et al. 2018). IOS Press sponsored the Best Student Paper Award which was won at COMMA 2018 by Lisa Andreevna Chalaguine from University College London for the paper "Argument Harvesting Using Chatbot".

\section{ArgDiaP Association (Argumentation, Dialogue, Persuasion)}

\subsection{ArgDiaP Community}

These events were organised under the auspices of the ArgDiaP Association - a Polish nationwide initiative dedicated to issues of argumentation, dialogue and persuasion (http://argdiap.pl/). Established in 2008, ArgDiaP has been continuously providing infrastructure facilitating the networking process and fostering research on argumentation in Poland, including the research of the Polish School of Argumentation. Initially, ArgDiaP acted as an informal organisation, but on 2nd July 2018 it became an official asso- 
ciation. The Polish School of Argumentation, with ArgDiaP support, integrates various disciplines and institutions across Poland, in which scholars are dedicated to understanding the phenomenon of the force of argument. In 2014, fifty-five authors (Budzyńska et al. 2014; argdiap.pl/manifesto) declared its Manifesto which sets up the foundations of the School's research programme.

\subsection{ArgDiaP workshops}

This year there were two workshops collocated with the ArgDiaP conference: 2nd MET-ARG (Methodologies for Research on Legal Argumentation) and 1st MET-RhET (Methodologies for Research on Rhetoric).

The aim of the 2nd Workshop on Methodologies for Research on Legal Argumentation (MET-ARG) was to provide space for the exchange of methodological ideas concerning research on argumentation related to evidence and proof (http://argdiap.pl/metarg2018). The workshop gathered eight presenters and a large audience. In the keynote speech entitled "Representing (Legal) Argumentation Schemes with Constraint Handling Rules", Thomas F. Gordon presented a high-level declarative programming language for representing (legal) argumentation schemes, where schemes represented in this language can be easily validated by domain experts. The other presenters analyzed evidence and proof from the viewpoints of various disciplines: law, artificial intelligence, philosophy, logic, etc. Each presentation was followed by a vivid and fruitful discussion. The peer-reviewed full versions of the workshop papers are planned to be published as a 2019 special issue of the Journal of Applied Logics - IfCoLoG Journal of Logics and their Applications (College Publications).

The MetRhet (Methodologies for Research on Rhetoric) workshop on "Conflict and Controversy", co-organised by the Polish Rhetorical Society, explored rhetorical approaches towards conflict (http://argdiap.pl/metrhet 2018). The workshop brought together 16 scholars and a good-sized audience. In the keynote speech - "The force of rhetoric" - Jean Goodwin (NCSU, USA) showed how rhetorical performances help to change the world within which citizens strive for their diverging ends. The session "Rhetorical approaches towards conflict and conflict solution" focused on the rhetorical tools able both to provoke as well as to resolve social problems. The main issue discussed at the session "Rhetorical literacy as a weapon in the era of eristic" was the rhetorical awareness needed in civic societies. The session "Rhetoric and eristic in local debates" addressed emotions relevant in small communities. In the last part - "Models and analyses of conflicts and controversies" - the arguments based on ethos, logos, and pathos were dis- 
cussed. The workshop showed the attractiveness of the rhetorical framework in the studies of conflict discourse.

\subsection{ArgDiaP Conference}

ArgDiaP conferences have been organised since 2008. The 2018 edition was the 16th and its main theme was "Argumentation and Corpus Linguistics" (http://argdiap.pl/argdiap2018). The study of linguistics has been revolutionised in recent years by the availability of computerised corpora containing millions of searchable texts and allowing for the testing of a wide range of theories and hypotheses on the use of language. Argumentation studies are increasingly ready to take advantage of technology in similar ways with the development of argument mining techniques. This event sought to bring together linguists and argumentation scholars who are interested in the use of corpora, in order that they may share knowledge and experiences and examine the ways in which studies in the two areas may complement each other.

The 16th ArgDiaP consisted of 2 invited and 8 contributed talks addressing this issue. Invited talks were presented by Chris Reed (Centre for Argument Technology, University of Dundee, UK) and Bonnie Webber (Institute for Language, Cognition and Computation, University of Edinburgh, UK). Contributed talks covered such topics as: annotating argument schemes, mining meta-arguments, modelling questions in dialogues, corpus analysis, and corpus creation.

A special issue of the journal Argumentation containing papers from both the ArgDiaP conference and the MET-RhET workshop will be published in 2019.

\section{R E F E R E N C E S}

Budzynska, K., Araszkiewicz, M., Bogołębska, B., Cap, P., Ciecierski, T., Debowska-Kozlowska, K., Dunin-Kęplicz, B., Dziubiński, M., Federowicz, M., Gomolińska, A., Grabowski, A., Hołówka, T., Jochemczyk, Ł., Kacprzak, M., Kawalec, P., Kielar, M., Kisielewicz, A., Koszowy, M., Kublikowski, R., Kulicki, P., Kuzio, A., Lewiński, P., Lichański, J. Z., Malinowski, J., Marciszewski, W., Nieznański, E., Pietrzak, J., Pogonowski, J., Puczyłowski, T. A., Rytel, J., Sawicka, A., Selinger, M., Skowron, A., Skulska, J., Smolak, M., Sokół, M., Sowińska, A., Stalmaszczyk, P., Stawecki, T., Stepaniuk, J., Strachocka, A., Suchoń, W., Szymanek, K., Tomczyk, J., Trypuz, R., Trzęsicki, K., Urbański, M., Wasilewska-Kamińska, E., Wieczorek, K. A., Witek, M., Wybraniec-Skardowska, U., Yaskorska, O., Załęska, M., Zdanowski, K., and Żurek, T. (2014) The Polish School of Argumentation: A Manifesto. Argumentation, Springer, 28(3): 267-282. 
Modgil, S., Budzynska, K., Lawrence, J. (2018, Eds.) Proceedings of 7th International Conference on Computational Models of Argument COMMA 2018, Frontiers in Artificial Intelligence and Applications, Volume 305, pp. 1-480.

\section{Full list of authors}

Katarzyna Budzynska

Polish Academy of Sciences \& University of Dundee ORCID 0000-0001-6640-7207

Michał Araszkiewicz Jagiellonian University in Kraków ORCID 0000-0003-2524-3976

Agnieszka Budzyńska-Daca University of Warsaw

ORCID 0000-0003-1002-7197

Martin Hinton

University of Łódź

ORCID 0000-0003-0374-8834

John Lawrence

University of Dundee

ORCID 0000-0003-1162-097X

Sanjay Modgil

King's College London

ORCID 0000-0002-7873-8086

Matthias Thimm

Universität Koblenz-Landau

ORCID 0000-0002-8157-1053

Jacky Visser

University of Dundee

ORCID 0000-0003-2778-0847
Marcin Koszowy

University of Białystok

\& Polish Academy of Sciences

ORCID 0000-0001-5553-7428

\section{Katie Atkinson \\ University of Liverpool \\ ORCID 0000-0002-5683-4106}

Kamila Dębowska-Kozłowska Adam Mickiewicz University in Poznań ORCID 0000-0002-5039-6133

\section{Magdalena Kacprzak}

Białystok University of Technology

ORCID 0000-0002-9464-7686

\section{Paweł Łupkowski}

Adam Mickiewicz University in Poznań ORCID 0000-0002-5335-2988

\section{Barłomiej Skowron}

Warsaw University of Technology

ORCID 0000-0002-6544-7706

\section{Mariusz Urbański}

Adam Mickiewicz University in Poznań ORCID 0000-0002-8682-5307

\section{Maria Załęska}

University of Warsaw

ORCID 0000-0003-2973-0173

\section{Tomasz Żurek}

Maria Curie-Skłodowska University in Lublin

ORCID 0000-0002-9129-3157 